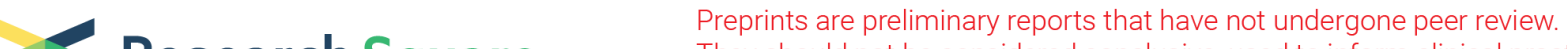 Research Square They should not be considered conclusive, used to inform clinical practice, or referenced by the media as validated information.
}

\section{Sorafenib in the treatment of Hepatocellular carcinoma (HCC) patients with microvascular infiltration: a systematic review and meta-analysis}

Wang Gu

Anhui Medical University Third Affiliated Hospital

Zhong Tong ( $\square$ tougao2425@163.com )

Anhui Medical University Third Affiliated Hospital https://orcid.org/0000-0002-8869-2691

\section{Research article}

Keywords: Sorafenib; Hepatocellular carcinoma (HCC); Microvascular invasion (MVI).

Posted Date: April 21st, 2020

DOI: https://doi.org/10.21203/rs.3.rs-23398/v1

License: (c) (1) This work is licensed under a Creative Commons Attribution 4.0 International License.

Read Full License

Version of Record: A version of this preprint was published at Journal of International Medical Research on August 1st, 2020. See the published version at https://doi.org/10.1177/0300060520946872. 


\section{Abstract}

Microvascular invasion has been shown to be an independent risk factor for liver cancer recurrence. Timely treatment can reduce the recurrence rate and prolong the total survival time. However, the effectiveness of sorafenib in treating HCC patients with microvascular invasion remains controversial. As of December 30, 2019, a comprehensive literature search has been conducted in PubMed, EMBASE, MEDLINE, web of science and Cochrane Library. A meta-analysis was conducted to assess the impact of sorafenib on mortality in HCC patients with microvascular involvement. Two researchers independently reviewed and cross-checked independent reports with sufficient information. Four studies were selected and reported 950 cancer events and 505 cancer deaths. The results showed that sorafenib could improve the survival rate of liver cancer patients with microvascular invasion ( $R R=1.369 ; 95 \%$ confidence interval (CI) 1.193-1.570; $\mathrm{P}<0.001)$. However, given the potential for residual confounding, the results should be interpreted with caution. Further prospective studies still need to confirm the prognostic benefits of sorafenib.

\section{Introduction}

Liver cancer is the second leading cause of cancer death worldwide. Hepatocellular carcinoma (HCC) is the third leading cause of cancer-related death, the fifth most common cancer in men and the seventh most common cancer in women. [1, 2]. Partial hepatectomy is the preferred treatment for patients with early hepatocellular carcinoma (HCC) [3], but about $70 \%$ of patients relapse within 5 years after hepatectomy [4], and about $30 \%$ of patients with recurrent HCC perform poorly at the time of mid-term diagnosis [5]. Hepatocellular carcinoma with microvascular tumor invasion (MVI) is very common, and microvascular invasion is often associated with early recurrence of tumors and reduced survival. [6-8]. Microvascular invasion occurs in approximately $15-60 \%$ of HCC patients. Relevant studies have shown that microvascular invasion is an independent risk factor for early recurrence [9-12]. Although there are some studies that show that some complementary therapies can help $[13,14]$, there is still no commonly accepted adjuvant therapy after hepatectomy[15].

Sorafenib is an effective multi-kinase inhibitor that inhibits tumor angiogenesis and proliferation by interfering with the binding of serine/threonine kinases to receptor tyrosine kinases [16]. In addition, sorafenib is known to have effects on both tumor cells and endothelial cells[17]. Despite multiple studies, no reliable predictive biomarkers have been identified for the response of HCC patients to sorafenib, including sorafenib targets such as MAPK/ERK or VEGF. However, sorafenib is considered an effective treatment for advanced liver cancer, and this treatment has been maintained for nearly a decade. [18].

In view of the global prevalence of liver cancer and the high mortality of cancer patients, it is of great clinical significance to explore sorafenib in the treatment of liver cancer in daily practice. In addition, they are crucial in the area of public health, as a modest increase in cancer risk translates into a huge social burden. These conditions prompted us to study the effect of sorafenib on cancer mortality more precisely. We carefully read the relevant original reports and combined their data to try to obtain meaningful clues. 


\section{Methods}

\section{Search strategy}

The two studies independently searched the Medline, Embase, PubMed, Cochrane Libraries,and Web of science databases for all relevant articles. Medical subject heading terms used in the search included "liver cancer ", "Hepatocellular carcinoma (HCC)", “Hepatic carcinoma”, "hepatoma”, "sorafenib", "microvascular invasion". The study's title and abstract were independently reviewed by the two authors, excluding studies that did not answer relevant research questions. The full text of the remaining articles, including references, was examined to determine if they contained relevant information. When incomplete information was available, attempts were made to contact the corresponding author of the study for more information. Figure 1 shows the literature screening process..

\section{Selection criteria}

If the cohort and case-control studies or randomized controlled trial of sorafenib therapy associated with microvascular invasion of hepatocellular carcinoma (HCC), in which the experimental group for the use of sorafenib therapy, treatment group does not contain sorafenib, and study the related risk ratio (hr)/relative risk (RR)/odds ratio (or) and corresponding 95\% confidence intervals (Cls), or provides ample research data will be incorporated in the analysis. Inclusion is not limited by language, time, nationality and other factors. If the study object is the same population, select a more complete study to be included in the analysis.

\section{Data extraction}

In the Endnote version X9, references are merged together for ease of administration. Two authors independently completed the literature search and evaluated the full text. For the selected literature, two authors read the title, abstract and full text of the article. Authors in each eligible studies to extract the relevant data, to extract the study's lead author, publication date, country, research methods, data sources, research time, fixed number of year of follow-up, the study of the characteristics of the object (age, gender, exposure, the definition of a test dose and duration of the relevant risk assessment (including hr, RR or) and $95 \%$ confidence interval and relevant confounding factors. The authors did all this work independently. Because subjects in some studies used combination therapy, we defined the experimental group as treatment with sorafenib and the control group as non-treatment with sorafenib.

\section{Quality assessment}

The Newcastle Ottawa scale[19] was used to evaluate the quality of the cohort study. In this scale, the study was divided into three categories: subject selection (4 stars), study group comparability (2 stars), result / exposure assessment ( 3 stars). The quality adopts star system, the highest 9 stars, 0-5 stars are low quality, 6-9 stars are high quality. The characteristics of the study are shown in Table 1.

\section{Statistical analysis}


The statistical analysis in this article used the 15th generation of STATA software (STATA, College Station, TX, USA). The probability values ( $P$ values) of all statistical results were bilateral, and $P<0.05$ was considered statistically significant. Higgins and Thompson's 12 was used to assess heterogeneity between studies. When $\mathrm{I}^{2}>50 \%$ is represented as large heterogeneity, $\mathrm{I}^{2}<50 \%$ indicates small heterogeneity. [20], DerSimonian and Laird random effect model (REM) is used as pooling method, otherwise, fixed effect model (FEM) is used as pooling method.

\section{Results}

Four related studies were reviewed[21-24], with a total of about $950 \mathrm{HCC}$ patients with microvascular invasion. Sorafenib significantly improved survival in HCC patients with microvascular invasion compared to those without sorafenib treatment $(R R=1.369,95 \%$ confidence interval $(\mathrm{Cl}) 1.193,1.570 ; \mathrm{P}<$ 0.001). There was no significant heterogeneity between the 4 included studies $\left(P=0.352>0.01 ;\left.\right|^{2}=8.2 \%\right)$ The relevant results are shown in Fig. 2. The results of publication bias show that there is no publication $\operatorname{bias}(z=1.02>0.05, \operatorname{Pr}>|z|=0.308)$, The funnel is shown in Fig. 3 . Through the sensitivity analysis, it can be concluded that there is no significant difference among the four studies, with good consistency (Fig. 4).

\section{Discussion}

$\mathrm{HCC}$ is one of the most common cancers in the world [25]. In the past few decades, with the progress of technology, the treatment of liver cancer has made great progress. Surgical resection remains the first-line treatment for early and intermediate HCC. The recurrence rate after tumor resection is high, but the longterm survival rate of patients is low [26, 27]. Microvascular invasion is a manifestation of tumor invasion of endothelial cells. Microvascular invasion often leads to poor prognosis. [28, 29]. Hepatectomy is a safe and effective method to treat liver cancer, however, microvascular invasion greatly increases the risk of cancer recurrence after hepatectomy. Several studies have demonstrated that radiofrequency ablation and TACE are effective for recurrence after hepatectomy and for patients with hepatocellular carcinoma with venular invasion. [30-32]. An animal study in mice found that sorafenib prevented the recurrence and metastasis of liver tumors. [33]. One study found that the effect of sorafenib adjuvant chemotherapy in patients with liver cancer with MVI was positive after surgery. [34].Therefore, theoretically, the antiangiogenesis, apoptosis and proliferation effects of sorafenib make it an ideal drug choice after hepatectomy, but there are few related studies.

Although the mechanism of sorafenib's action is not very clear, related studies suggest that sorafenib may be an enzyme inhibitor, whose effect is to inhibit vascular endothelial hyperplasia and thus inhibit microvascular invasion. For example, sorafenib can block serine/threonine kinases (c-RA and b-RAF) and receptor tyrosine kinases (vascular endothelial growth factor receptors 2 and 3, platelet-derived growth factor receptor levels, FMS tyrosine kinase 3) [35], VEGF is a major factor in the mechanism of tumor angiogenesis. An animal study showed that sorafenib could significantly inhibit the growth and migration of cancer cells [33].Wang et al. demonstrated that sorafenib as an adjuvant therapy for liver cancer can 
prevent early recurrence after hepatectomy[36]. The study found that the use of sorafenib can significantly reduce the recurrence rate and improve the survival rate of patients with liver cancer. [3740]. However, the results of some studies are not identical.The results show that although sorafenib can reduce the mortality of patients after radical hepatectomy and reduce the operation time, it can not reduce the risk of tumor recurrence.[41].

At present, there are few relevant studies on the efficacy of sorafenib on liver cancer patients with venereal metastasis, and the sample size of existing studies is relatively small, so we decided to conduct a systematic analysis based on relevant studies. This review systematically reviewed the efficacy of sorafenib in the treatment of hepatocellular carcinoma patients with venule invasion in four studies. We conduct relevant literature searches in multiple databases and hope to collect articles as comprehensively as possible. And through rigorous scientific methods to extract valid data in relevant articles. Because of the potential confounding factors in relevant studies, we tried to exclude relevant interfering factors to collect as accurate data as possible. A systematic analysis of four studies involving 950 patients with hepatocellular carcinoma with venular invasion by our team found that the use of sorafenib significantly improved the survival rate of patients with low hepatocellular carcinoma with venular invasion compared with patients without sorafenib. $(R R=1.369 ; 95 \% c i, 1.193-1.570 ; P<0.001)$, and there was no significant heterogeneity between studies $\left(I^{2}=8.2 \%\right)$. Since there was no significant heterogeneity between studies, we did not further explore the sources of heterogeneity. Our systematic analysis also has certain limitations, for example, the adjustments included in the study may be incomplete and inconsistent. Confounders such as the patient's own status (tumor stage and related complications) and the lack of detail on sorafenib use (dose and duration) in most studies will affect the overall analysis. In addition, treatment information is obtained through prescriptions in the patient's medical records, so the difference between the prescribed dose and the actual dose may affect the outcome.

\section{Conclusion}

In summary, the use of sorafenib reduced the mortality of HCC patients with venereal invasion, and most other exploratory analyses confirmed this effect. However, Considering the presence of confounding factors, the conclusions should be interpreted with caution. At the same time, due to the limitation of relevant research design, this outcome is somewhat controversial. Therefore, more clinical trials are needed to prove whether sorafenib is effective in the treatment of hepatocellular carcinoma patients with venular invasion.

\section{Abbreviations}

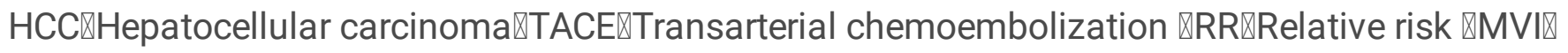
Microvascular invasion $₫ A A S L D \bigotimes A m e r i c a n$ Association for the Study of Liver Diseases.

\section{Declarations}


Acknowledgements

We would like to express our sincere gratitude to: the relatives of the patient $\$ the staff of the hepatobiliary surgery ward.

\section{Funding}

The authors declare that they have no funding source.

Availability of data and materials

Not applicable.

Ethics approval and consent to participate

Not applicable.

Consent for publication

Written informed consent was obtained from the patient and patient's next-of-kin for publication of this case report and any accompanying images. A copy of thewritten consent is available for review by the Editor-in-Chief of this journal.

Competing interests

The authors declare that they have no competing interests.

\section{References}

1. R Lozano, M Naghavi, K Foreman, S Lim, K Shibuya, V Aboyans, J Abraham, T Adair, R Aggarwal, SY Ahn et al: Global and regional mortality from 235 causes of death for 20 age groups in 1990 and 2010: a systematic analysis for the Global Burden of Disease Study 2010. 2012, 380(9859):20952128.

2. J Ferlay, HR Shin, F Bray, D Forman, C Mathers, cancer Parkin DM \%J International journal of: Estimates of worldwide burden of cancer in 2008: GLOBOCAN 2008. 2010, 127(12):2893-2917.

3. JM Llovet, A Burroughs, Lancet Bruix J \%J: Hepatocellular carcinoma. 2003, 362(9399):1907-1917.

4. T Onoe, M Yamaguchi, T Irei, K Ishiyama, T Sudo, N Hadano, M Kojima, H Kubota, R Ide, H Tazawa et al: Feasibility and efficacy of repeat laparoscopic liver resection for recurrent hepatocellular carcinoma. 2019.

5. DP Ou, LY Yang, GW Huang, YM Tao, X Ding, gastroenterology Chang ZG \%J World journal of: Clinical analysis of the risk factors for recurrence of HCC and its relationship with HBV. 2005, 11(14):2061-2066. 
6. Cheung T. K., LAI C.-L., WONG B. C.-Y., FUNG J., Pharmacology M.-F. YUEN \%J Alimentary, Therapeutics: Clinical features, biochemical parameters, and virological profiles of patients with hepatocellular carcinoma in Hong Kong. 24(4):573-583.

7. S Cortese, J Morales, L Martín, S Kayser, A Colón, E Ramón, espanola Tellado JM \%J Cirugia: Hepatic resection with thrombectomy in the treatment of hepatocellular carcinoma associated with macrovascular invasion. 2020, 98(1):9-17.

8. LH Feng, H Dong, WY Lau, H Yu, YY Zhu, Y Zhao, YX Lin, J Chen, MC Wu, research Cong WM \%J Journal of cancer et al: Novel microvascular invasion-based prognostic nomograms to predict survival outcomes in patients after R0 resection for hepatocellular carcinoma. 2017, 143(2):293-303.

9. V Mazzaferro, JM Llovet, R Miceli, S Bhoori, M Schiavo, L Mariani, T Camerini, S Roayaie, ME Schwartz, GL Grazi et al: Predicting survival after liver transplantation in patients with hepatocellular carcinoma beyond the Milan criteria: a retrospective, exploratory analysis. 2009, 10(1):35-43.

10. M Du, L Chen, J Zhao, F Tian, H Zeng, Y Tan, H Sun, J Zhou, cancer Ji Y \%J BMC: Microvascular invasion (MVI) is a poorer prognostic predictor for small hepatocellular carcinoma. 2014, 14:38.

11. KC Lim, PK Chow, JC Allen, GS Chia, M Lim, PC Cheow, AY Chung, LL Ooi, surgery Tan SB \%J Annals of: Microvascular invasion is a better predictor of tumor recurrence and overall survival following surgical resection for hepatocellular carcinoma compared to the Milan criteria. 2011, 254(1):108-113.

12. M Rodríguez-Perálvarez, TV Luong, L Andreana, T Meyer, AP Dhillon, oncology Burroughs AK \% J Annals of surgical: A systematic review of microvascular invasion in hepatocellular carcinoma: diagnostic and prognostic variability. 2013, 20(1):325-339.

13. L Wang, W Wang, X Yao, W Rong, F Wu, B Chen, M Liu, S Lin, Y Liu, Oncotarget Wu J \% J: Postoperative adjuvant radiotherapy is associated with improved survival in hepatocellular carcinoma with microvascular invasion. 2017, 8(45):79971-79981.

14. JJ Sun, K Wang, CZ Zhang, WX Guo, J Shi, WM Cong, MC Wu, WY Lau, oncology Cheng SQ \% J Annals of surgical: Postoperative Adjuvant Transcatheter Arterial Chemoembolization After RO Hepatectomy Improves Outcomes of Patients Who have Hepatocellular Carcinoma with Microvascular Invasion. 2016, 23(4):1344-1351.

15. M Kudo, M Kitano, T Sakurai, diseases Nishida N \%J Digestive: General Rules for the Clinical and Pathological Study of Primary Liver Cancer, Nationwide Follow-Up Survey and Clinical Practice Guidelines: The Outstanding Achievements of the Liver Cancer Study Group of Japan. 2015, 33(6):765-770.

16. Sanoff H. K., Chang Y., Lund J. L., ONeil B. H., Dusetzina S. B. \%J Oncologist: Sorafenib Effectiveness in Advanced Hepatocellular Carcinoma.theoncologist.2015-0478.

17. SM Wilhelm, L Adnane, P Newell, A Villanueva, JM Llovet, therapeutics Lynch M \% J Molecular cancer: Preclinical overview of sorafenib, a multikinase inhibitor that targets both Raf and VEGF and PDGF receptor tyrosine kinase signaling. 2008, 7(10):3129-3140.

18. AL Cheng, YK Kang, Z Chen, CJ Tsao, S Qin, JS Kim, R Luo, J Feng, S Ye, TS Yang et al: Efficacy and safety of sorafenib in patients in the Asia-Pacific region with advanced hepatocellular carcinoma: a 
phase III randomised, double-blind, placebo-controlled trial. 2009, 10(1):25-34.

19. epidemiology Stang A \%J European journal of: Critical evaluation of the Newcastle-Ottawa scale for the assessment of the quality of nonrandomized studies in meta-analyses. 2010, 25(9):603-605.

20. JP Higgins, SG Thompson, JJ Deeks, BMJ Altman DG \%J: Measuring inconsistency in metaanalyses. $2003,327(7414): 557-560$.

21. Y Huang, Z Zhang, Y Zhou, J Yang, K Hu, OncoTargets Wang Z \%J, therapy: Should we apply sorafenib in hepatocellular carcinoma patients with microvascular invasion after curative hepatectomy? 2019, 12:541-548.

22. Z Peng, S Chen, H Xiao, Y Wang, J Li, J Mei, Z Chen, Q Zhou, S Feng, M Chen et al: Microvascular Invasion as a Predictor of Response to Treatment with Sorafenib and Transarterial Chemoembolization for Recurrent Intermediate-Stage Hepatocellular Carcinoma. 2019, 292(1):237247.

23. XP Zhang, ZT Chai, YZ Gao, ZH Chen, K Wang, J Shi, WX Guo, TF Zhou, J Ding, WM Cong et al: Postoperative adjuvant sorafenib improves survival outcomes in hepatocellular carcinoma patients with microvascular invasion after R0 liver resection: a propensity score matching analysis. 2019, 21(12):1687-1696.

24. Zhang Z., Huang Y., Zhou Y., Yang J., Hu K., Wang Z.: Survival analysis of sorafenib in hepatocellular carcinoma patients with microvascular invasion after hepatectomy. Annals of Oncology 2018, 29.

25. Parkin D Max, Bray Freddie, JF Ferlay, Clinicians Paola Pisani \%J CA A Cancer Journal for: Global Cancer Statistics, 2002. 2005, 55(2):74-108.

26. Bruix Jordi, Sherman Morris \%J Hepatology: Management of hepatocellular carcinoma: An update. 2011, 53(3).

27. Bruix Jordi, Llovet Josep M.: Prognostic prediction and treatment strategy in hepatocellular carcinoma. 35(3):519-524.

28. Mazzaferro Vincenzo, Llovet Josep M, Miceli Rosalba, Bhoori Sherrie, Oncology Pietro Majno \% J Lancet: Predicting survival after liver transplantation in patients with hepatocellular carcinoma beyond the Milan criteria: a retrospective, exploratory analysis. 2009, 10(1):35-43.

29. Du Min, Chen Lingli, Zhao Jing, Tian Feng, Zeng Haiying, Tan Yunshan, Sun Huichuan, Zhou Jian, Ji Yuan \%J BMC Cancer: Microvascular invasion (MVI) is a poorer prognostic predictor for small hepatocellular carcinoma. 14(1):38.

30. Feng Xiaobin, Xu Ruocai, Du Xilin, Dou Kefeng, Qin Xiao, Xu Jun, Jia Weidong, Wang Zhiming, Zhao Hongzhi, Yang Shufa \%J American Journal of Gastroenterology: Combination Therapy With Sorafenib and Radiofrequency Ablation for BCLC Stage 0-B1 Hepatocellular Carcinoma: A Multicenter Retrospective Cohort Study. 109(12):1891-1899.

31. Qi Yao, Zhang Hongsen, Xiong Bin, Zheng Chuansheng: Combination of sorafenib and TACE inhibits portal vein invasion for intermediate stage HCC: a single center retrospective controlled study. 2017, 8(45):79012-79022. 
32. TY Lee, CC Lin, CY Chen, TE Wang, GH Lo, CS Chang, Medicine Chao Y \%J: Combination of transcatheter arterial chemoembolization and interrupted dosing sorafenib improves patient survival in early-intermediate stage hepatocellular carcinoma: A post hoc analysis of the START trial. 2017, 96(37):e7655.

33. Feng Yu-Xiong, Wang Tao, Deng Yue-Zhen, Yang Pengyuan, Li Jing-Jing, Guan Dong-Xian, Yao Fan, Zhu Yin-Qiu, Qin Ying, Wang Hui \%J Hepatology: Sorafenib suppresses postsurgical recurrence and metastasis of hepatocellular carcinoma in an orthotopic mouse model. 2011, 53.

34. Roayaie Sasan, Blume Iris N., Thung Swan N., Guido Maria, Fiel Maria-Isabel, Hiotis Spiros, Labow Daniel M., Llovet Josep M., Schwartz Myron E.: A System of Classifying Microvascular Invasion to Predict Outcome After Resection in Patients With Hepatocellular Carcinoma. 137(3):850-855.

35. Tai Wei Tien, Cheng Ann-Lii, Shiau Chung-Wai, Huang Hsiang-Po, Huang Jui-Wen, Chen Pei-Jer, Chen Kuen-Feng: Signal transducer and activator of transcription 3 is a major kinase-independent target of sorafenib in hepatocellular carcinoma. 55(5):0-1048.

36. SN Wang, SC Chuang, Hepatology Lee KT \%J Hepatology research : the official journal of the Japan Society of: Efficacy of sorafenib as adjuvant therapy to prevent early recurrence of hepatocellular carcinoma after curative surgery: A pilot study. 2014, 44(5):523-531.

37. Sorafenib after resection improves the outcome of BCLC stage $\mathrm{C}$ hepatocellular carcinoma \% J World Journal of Gastroenterology. v.22(15):155-161.

38. Lei Zhuang, Tianfu Wen, Mingqing Xu, Jiayin Yang, Wentao Wang, Hong Wu, Yong Zeng, Lvnan Yan, Yonggang Wei, Ams Li Bo \%J Archives of Medical Science: Sorafenib combined with hepatectomy in patients with intermediate-stage and advanced hepatocellular carcinoma. 6:1383-1393.

39. Xia Feng, Wu Li Li, Lau Wan Yee, Huan Hong Bo, Bie Ping \%J World Journal of Gastroenterology: Adjuvant sorafenib after heptectomy for Barcelona Clinic Liver Cancer-stage $\mathrm{C}$ hepatocellular carcinoma patients. 2016, 22(23):5384.

40. Wang Shen Nien, Chuang Shih-Cheng, Lee King-Teh \%J Hepatology Research: Efficacy of sorafenib as adjuvant therapy to prevent early recurrence of hepatocellular carcinoma after curative surgery: A pilot study. 44(5):523-531.

41. Zhang Wei, Zhao Gang, Wei Kai, Zhang Qingxiang, Ma Weiwei, Song Tianqiang, Wu Qiang, Zhang Ti, Kong Dalu, Li Qiang \%J Bioscience Trends: Adjuvant sorafenib reduced mortality and prolonged overall survival and post-recurrence survival in hepatocellular carcinoma patients after curative resection: A single-center experience. 8(6):333-338.

\section{Tables}


Table1: Characteristics of included studies in the meta-analysis

\begin{tabular}{|c|c|c|c|c|c|c|c|c|c|}
\hline $\begin{array}{l}\text { Study } \\
\text { (year) }\end{array}$ & Design & Location & $\begin{array}{l}\text { Study } \\
\text { population }\end{array}$ & & $\begin{array}{l}\text { Total } \\
\text { subject }\end{array}$ & $\begin{array}{l}\text { NOS } \\
\text { score }\end{array}$ & $\begin{array}{l}\text { Definition } \\
\text { of } \\
\text { exposure } \\
\text { and } \\
\text { control }\end{array}$ & $\begin{array}{l}\text { Median } \\
\text { follow- } \\
\text { up, M }\end{array}$ & $\begin{array}{l}\text { Adjusting } \\
\text { factors }\end{array}$ \\
\hline $\begin{array}{l}\text { Yun Huang } \\
\square 2019 \square\end{array}$ & Cohort & China & $\begin{array}{l}\text { HCC patients } \\
\text { microvascular } \\
\text { infiltration }\end{array}$ & with & 49 & 6 & $\begin{array}{l}\text { Ex: Use } \\
\text { sorafenib }\end{array}$ & $\begin{array}{l}22.2 \\
\text { months }\end{array}$ & $\begin{array}{l}\text { Study } \\
\text { exposure }\end{array}$ \\
\hline $\begin{array}{l}\text { Zhenwei } \\
\text { Peng } \\
\square 2019 \square\end{array}$ & Cohort & China & $\begin{array}{l}\text { HCC patients } \\
\text { microvascular } \\
\text { infiltration }\end{array}$ & with & 127 & 6 & $\begin{array}{l}\text { Ex: } \\
\text { Sorafenib } \\
\text { with } \\
\text { TACE }\end{array}$ & $\begin{array}{l}34.5 \\
\text { months }\end{array}$ & $\begin{array}{l}\text { Study } \\
\text { exposure } \\
\text { and TACE }\end{array}$ \\
\hline $\begin{array}{l}\text { Xiuping } \\
\text { Zhang } \\
\square 2019 \square\end{array}$ & Cohort & China & $\begin{array}{l}\text { HCC patients } \\
\text { microvascular } \\
\text { infiltration }\end{array}$ & with & 728 & 7 & $\begin{array}{l}\text { Ex: Use } \\
\text { sorafenib }\end{array}$ & $\begin{array}{l}\text { No } \\
\text { report }\end{array}$ & $\begin{array}{l}\text { Study } \\
\text { exposure }\end{array}$ \\
\hline $\begin{array}{ll}\text { Xinyu } & \text { Bi } \\
\square 2019 \square & \end{array}$ & Cohort & China & $\begin{array}{l}\text { HCC patients } \\
\text { microvascular } \\
\text { infiltration }\end{array}$ & with & 46 & 6 & $\begin{array}{l}\text { Ex: Use } \\
\text { sorafenib }\end{array}$ & $\begin{array}{l}\text { No } \\
\text { report }\end{array}$ & $\begin{array}{l}\text { Study } \\
\text { exposure }\end{array}$ \\
\hline
\end{tabular}

\section{Figures}




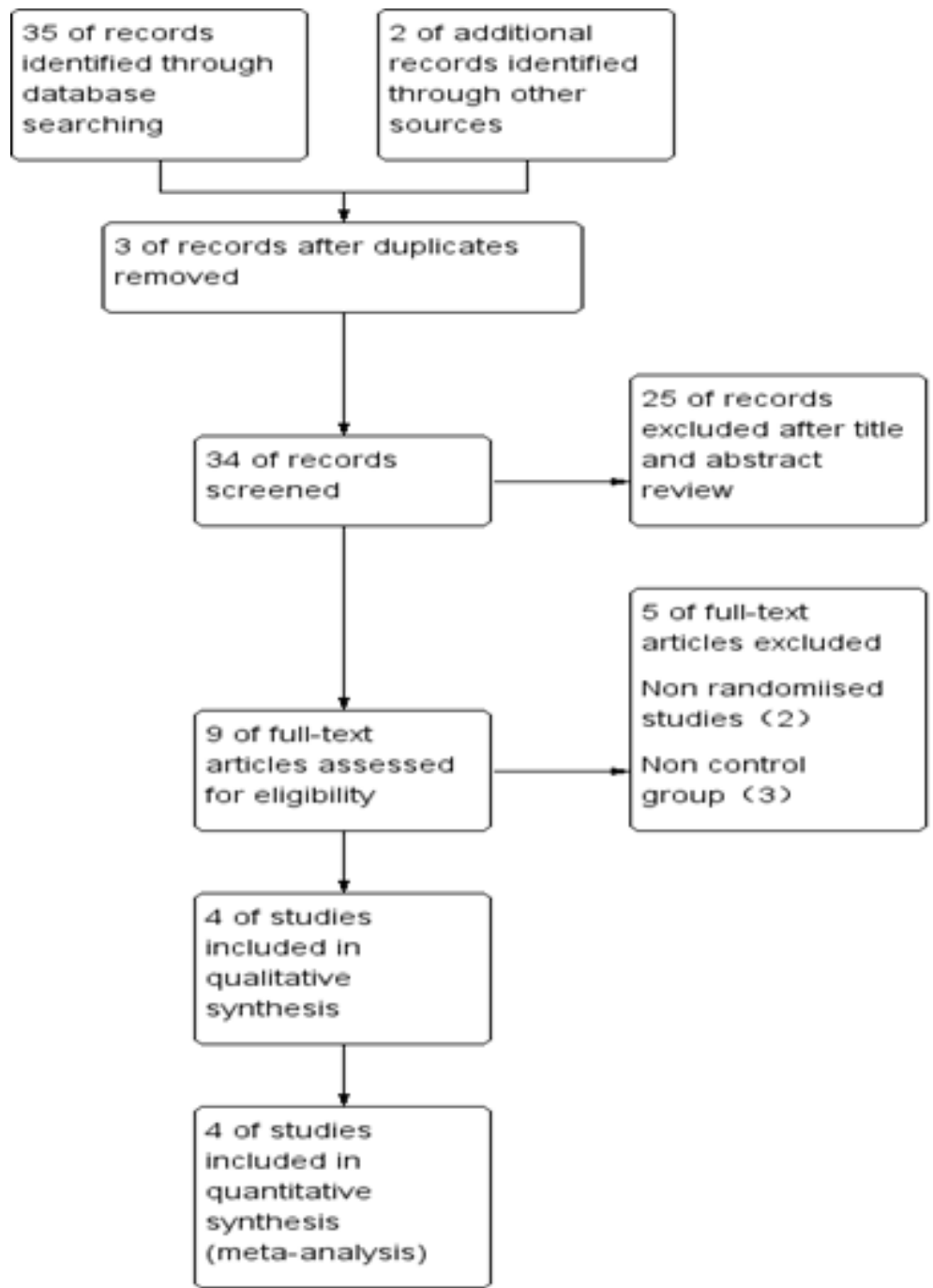

Figure 1

The flow chart of literature selection 


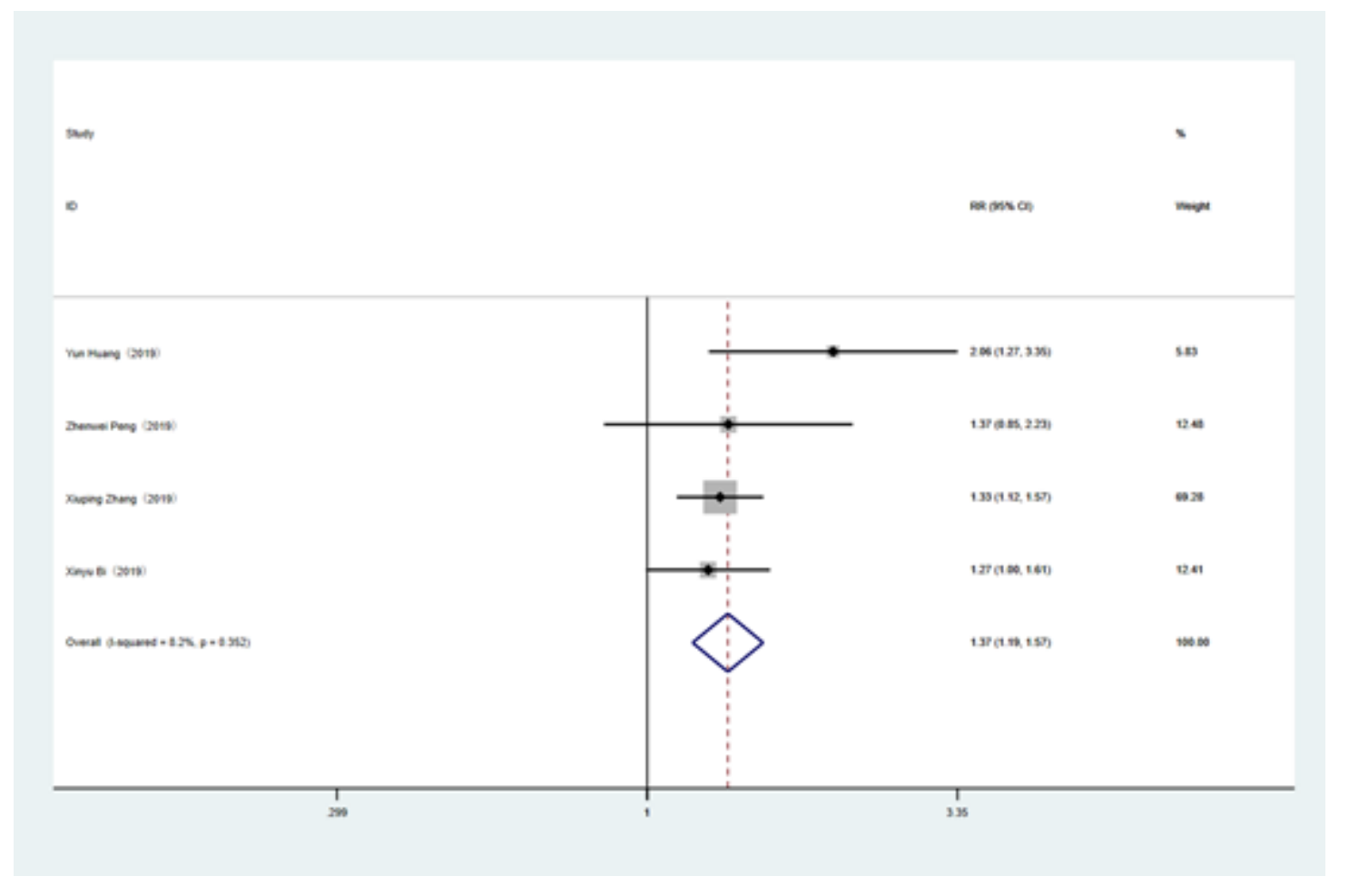

Figure 2

Forestplot of the relationship between the use of sorafenib and the outcome of treatment in patients with HCC with microvascular invasion.

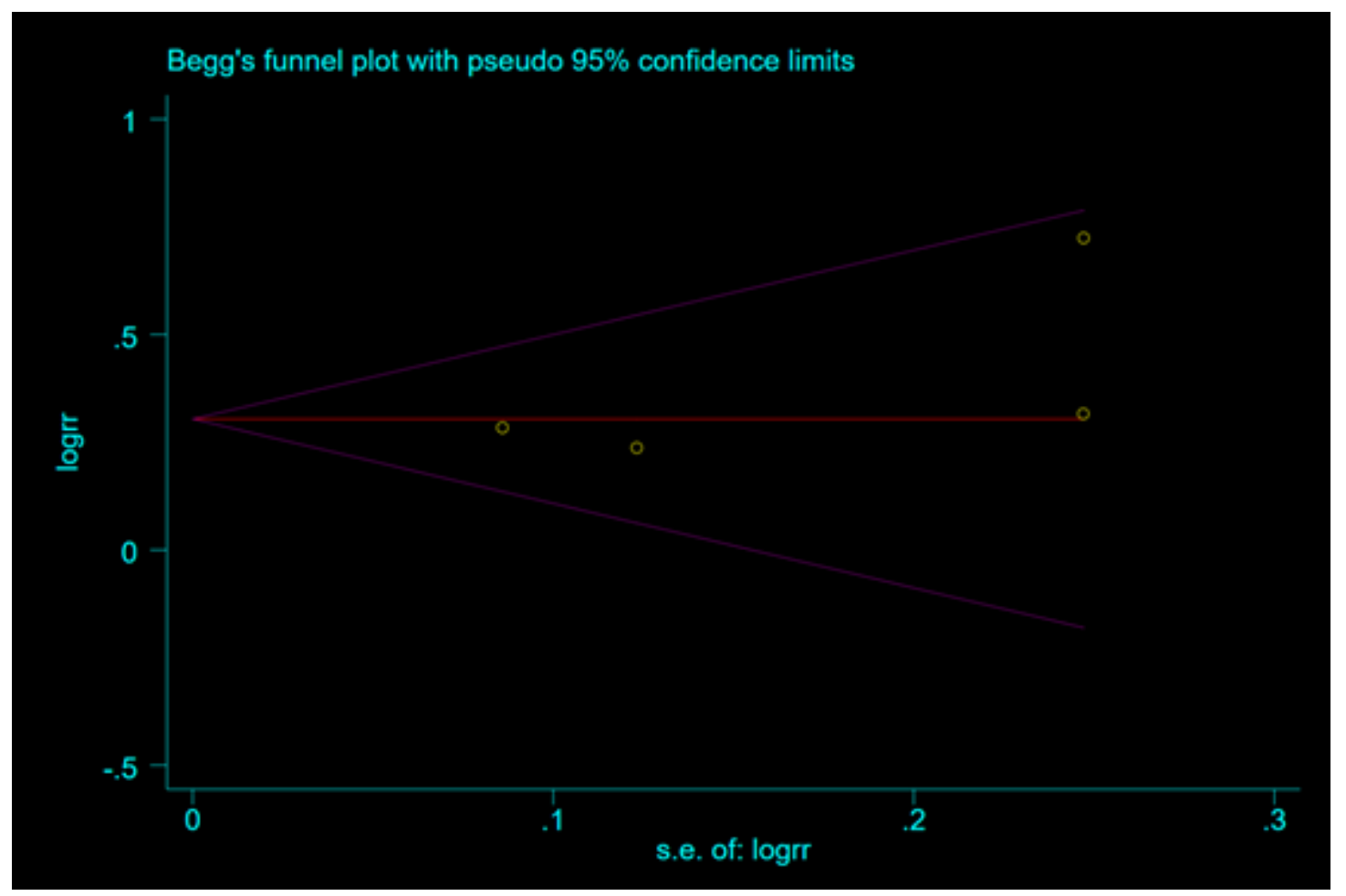

\section{Figure 3}

Begg's funnel polt 


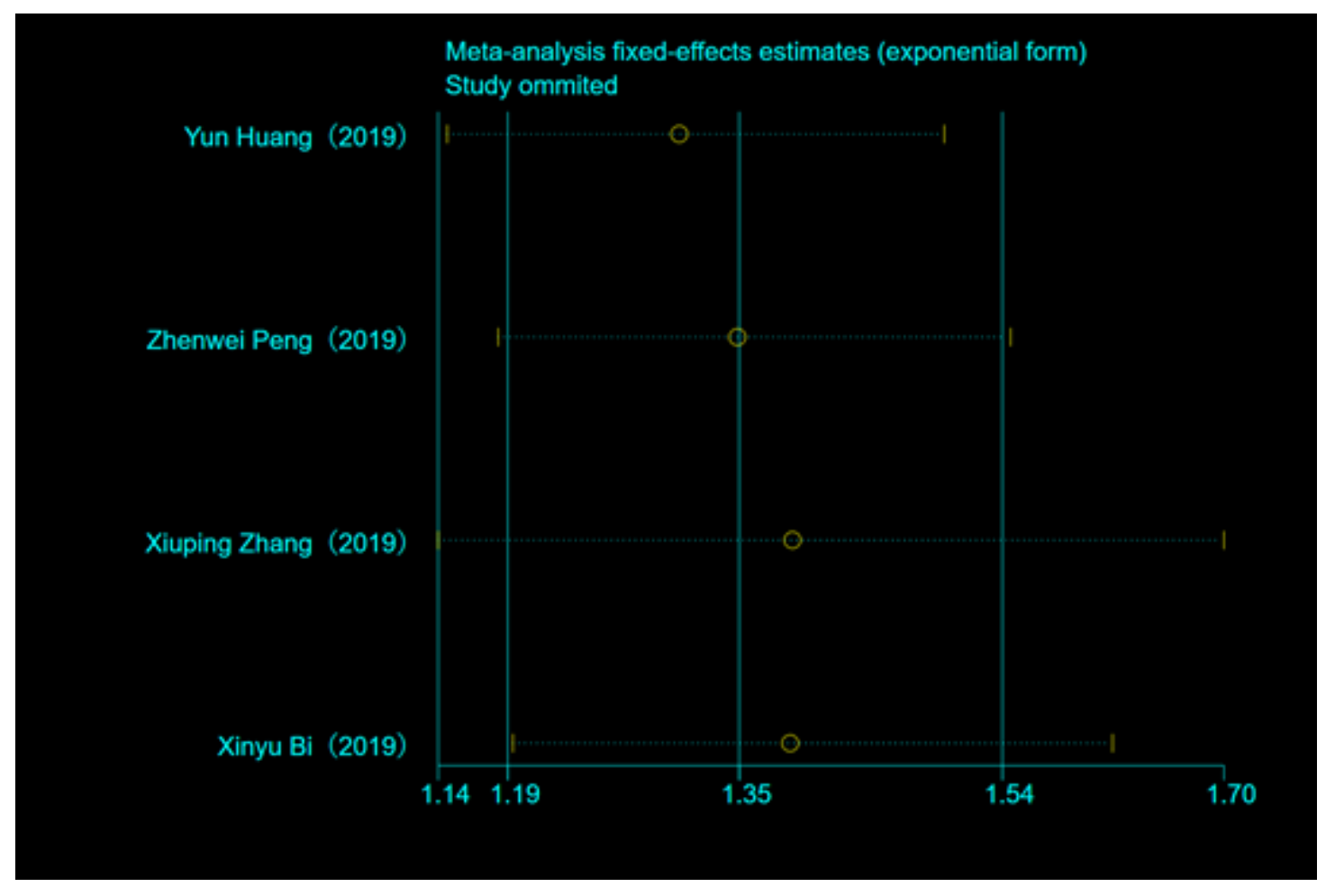

\section{Figure 4}

sensitivity analysis

\section{Supplementary Files}

This is a list of supplementary files associated with this preprint. Click to download.

- PRISMAchecklist.pdf 